\title{
Towards Modeling a Collaborative Environment for Extension of Professional Active Life
}

\author{
Hamideh Afsarmanesh ${ }^{1}$ and Luis Camarinha-Matos ${ }^{2}$ \\ ${ }^{1}$ Informatics Institute, University of Amsterdam, Science Park 107, \\ 1098 XG Amsterdam, The Netherlands \\ h.afsarmanesh@uva.nl \\ ${ }^{2}$ Faculty of Sciences and Technology, New University of Lisbon, \\ Quinta da Torre, 2829-516, Monte Capatica, Portugal \\ cam@uninova.pt
}

\begin{abstract}
Progress on computer networks is offering new conditions for individuals to remain active after their retirement. Furthermore, the scarcity of human resources and the increasing percentage of elder professionals in Europe have catalyzed the formation of a new type of collaborative community referred to as community of active senior professionals (CASP). These new networks aim to support retired professionals with their participation in socio-economic activities and thus remaining professionally active. As such, identification of their specificities as well as developing a descriptive model of CASPs is challenging. This paper characterizes the CASP environments and performs a first attempt towards identifying and modeling their constituent elements.
\end{abstract}

Keywords: Modeling associations of seniors, professional active life.

\section{Introduction}

Different forms of Collaborative Networks $(\mathrm{CN})$ have been investigated in research and emerged in practice during the last decades [6]. A community of active senior professionals is one type of such network, which has been established in a number of countries aiming to provide the base platform as well as to enhance the preparedness of retired professionals to participate in different activities and in doing so to remain professionally active. However, this type of collaborative networks still lacks sound models for their effective creation and operation. Proper characterization of these environments, namely the Community of Active Senior Professionals (CASP), shall represent and address its stakeholders and their activities, and support the configuration of temporary teams of senior professionals (TSPs) to respond to emerging opportunities. In this paper we introduce the following definitions: 
CASP constitutes an association of senior professional individuals that are largely autonomous, geographically distributed, and potentially heterogeneous in terms of their: capabilities, offered capacities, culture, system of values, etc., but sharing their main compatible and/or common goals of increasing their active professional life in the society and/or market, through co-working with others in Teams of Senior Professionals supported by computer networks, under the slogan of: "Together Everyone Achieves More!".

$\boldsymbol{T S P}$ is a collaborative network of individuals configured and established within the CASP in response to opportunities in the society and market that are in need of their wisdom and/or knowledge assets that they can offer, which as a consequence supports the retired professionals remaining professionally active.

SP (Senior Professional) is a retired professional who becomes a member of CASP in order to increase his/her chances of staying active and involved in the socioeconomic system, and perhaps also through getting involved in potential TSPs established through the CASP.

The paper addresses the modelling of such environments and the results from research work conducted in the ePAL project [5].

\section{Related Work on Modeling CNs}

As any other scientific discipline or engineering branch, collaborative networks require the development of its models, not only as a help to better understand the area, but also as the basis for the development of methods and tools for better decision making. It is however important to note that modeling is not only necessary for building software systems; in the context of collaborative networks, modeling is fundamental for understanding, managing, simulating or predicting the behavior of the network and its members, and certainly also for software development [2]. A number of models addressing different aspects of collaboration and particularly for virtual organizations and virtual enterprises are developed in research. Some examples of such models follow:

\footnotetext{
SCOR (Supply-Chain Operation Reference-model): developed as a standard diagnostic tool for supply-chain management in industries by providing guidelines regarding interactions among stakeholders [4].

VERAM (Virtual Enterprise Reference Architecture and Methodology): Aims at providing guideline for increasing preparedness of entities involved in the networks for efficient creation of virtual enterprises. VERAM also facilitates modeling processes through provision of guidelines on how to build the models and how to identify the common characteristics of the virtual enterprise and networks [11].

EGA (Enterprise Grid Alliance): Defines the terminology and glossary of grid computing and identifies various components, interfaces, interactions and data models [8]. It enables interoperability among heterogeneous grid applications and improves integration of grid services.

FEA (Federal Enterprise Architecture): Developed by the US office of Management and Budget $(\mathrm{OMB})$ for the purpose of supporting the identification of opportunities to simplify the processes and unify work across the agencies and within the lines of business of the US Federal government [9].
}

Some attempts have been made by researchers to develop generic models, frameworks and architectures for collaborative networks. An example of such attempt is 
ARCON ( $\underline{A} \underline{R}$ eference model for Collaborative Networks) [1]. ARCON introduces multiple modeling perspectives, including: environment characteristics, life cycle stages, and modeling intents.

As a new form of collaborative network for extending active life of senior professionals, CASPs are emerging as a special kind of CNs, primarily aiming to serve as preparedness environments for senior professionals towards remaining professionally active in their society. As such, the entities in these environments and their related interactions, behavior and processes need to be properly addressed by a reference modeling framework such as ARCON. Besides the study of a number of running networks of senior professionals, as addressed in detail in [3], as a pre-step to the ARCON definition of this environment, this paper contributes to provision of general characteristics, a few example scenario definitions, and a first attempt to identification of its constituents and its modeling.

\section{Characterizing ePAL Scenario}

Scenarios are widely used by organizations of all types, to better understand different ways that future events might unfold. Scenarios are used to characterize an environment for the purpose of identifying its constituent entities, behaviour, processes, life cycle, etc. In relation to the vision for the extension of professional life of elderly, a number of scenarios are developed to support understanding of different future possibilities regarding the enhancement of active life of senior professionals, as well as which events are probable to occur in future. Scenarios are also applied in the ePAL project to identify the stakeholders that will be involved in or impacted by this environment. Developed ePAL environment's scenarios address among others, aspects related to: (i) Technologies that need to be developed or tuned to support involvement of SPs in economical activities, (ii) Policies, rules and regulations that need to be formulated to favour active life of SPs, (iii) Interactions and related motivations among senior professionals and working forces, and (iv) Responsibilities of governments and other regulatory organs in enhancing activeness of SPs.

To enhance the presentation of the main contributions of this paper in regards to the modelling of this environment, namely in section 4, we present below three example scenarios of the ePAL environments. They specifically address: (1) association of SPs, (2) some problems and solutions faced by SPs, (3) provision of services by SPs.

\section{Scenario 1: Senior professionals association}

Mario is a senior electrical engineer that used to work for the national energy distributor as a public installations analyst and inspector. Although 65 years old he is a healthy man and felt frustrated for being obliged to retire so soon and at the same time depressed because he was at home with nothing interesting to do; he was feeling that he needed to give his brain some activity. One day, when navigating on the Internet, Mario found a website that attracted his attention - the ActiveSeniors Community. This website supported a community of senior people that was created out of the necessity of people to remain active after retirement through sharing with others their experiences, skills and knowledge. The main objective of ActiveSeniors is providing professional assistance to people, companies or organizations located in developing countries through unpaid/volunteering senior expertise.

Mario felt enthusiastic with the ActiveSeniors Community, especially with the idea of travelling to a new country and of putting his brain in motion again, and registered immediately as a new member. After 
the registration process Mario received a welcome letter and a collection of information containing the community rules. A couple of months later, Mario was still waiting to be contacted for an assignment and he started to feel anxious with the situation and remembered to start looking for missions. After a couple of days searching he found a small electrical company in Cabinda, Angola, that was passing severe financial problems. Mario contacted both ActiveSeniors and the small Angolan company and after all the arrangements were properly made Mario went to Cabinda. When Mario returned from Angola he was so happy that his relatives realized the importance of keeping retired people active...

In fact, contributing to help a region in need and also having the opportunity to travel was a great reward, specially considering that Mario's pension is enough for his needs. But the lack of opportunities to contribute is something that still worries him ... By the way, thinking about the difficulties, he also felt a bit uncomfortable for having to perform his mission alone and having to do some field work in Cabinda to better understand the problem before he actually could contribute to solve it.... As a result his contribution was a bit limited as the resources for the mission ended...

Challenges: A great number of senior/retired communities working on a voluntary basis exist nowadays. Examples can be for instance, Seniors Experts Benevoles - EGEE based in France, or SECOT in Spain. Nevertheless what commonly happens in these communities is that members lose interest due to:

1. The fact that there are not many opportunities to get involved; there are more volunteers than tasks.

2. Communities do not have a good incentive/motivation system for its members; this could be because they cannot evaluate the state of the community and interact adequately.

3. Not being paid for their missions, even if it was a symbolic remuneration it would give them a different motivation.

4. As pensions are getting lower, many potential new members of the associations cannot afford to do much voluntary work as they might need to find some complementary sources of income.

5. Working alone in a mission does not promote socialization and is sometimes risky.

Therefore, some challenges include:

(i) Development of new operational models, including more effective brokerage of opportunities.

(ii) Implementation of more effective mechanisms to make the community known.

(iii) Design and development of advanced ICT platforms to better support socialization and team work.

(iv) Find new mechanisms to facilitate interactions between seniors and the receiving entities.

(v) Combine models of voluntary work with other schemes providing some payment or fringe benefits.

\section{Scenario 2: Identifying Problems and providing solutions}

Last year Jane was an employee of a hoe manufacturing industry that faced job redundancy. Following a difficult life in the city, six months ago, she decided to go back to her home village in a far remote area. After arriving at the village she learned that there are a number of individuals and small groups of people who are producing traditional hoes manually. Although, these traditional hoes are of relatively less quality as the ones produced by industries but they are cheap and thus affordable by peasants in the village. Jane realized that these craftsmen produce small number of hoes than their capabilities and cannot even sell them as little as they produce. However the craftsmen themselves could not exactly pin-point their problems. She knew from the past that such groups of people can acquire support for knowledge and experience provided through associations of senior professionals. Thus the next day she decided to go to the near town to visit one association of senior professionals. At the office of the association she met the administrator, a retired person who used to be district development officer. After explaining to him the purpose of her visit the administrator told her that the members of the association could provide support of knowledge when the problem is clearly defined. She was further told that in past some senior professionals were sent to some areas to solve problems; however they found out that the problems were not in their areas of expertise. Therefore, she needs to workout herself and clearly define what kind of knowledge is needed to those local craftsmen. Lastly Jane was told that at the district office where the administrator used to work there is an office responsible for entrepreneurship. So she was told to try to get support from that office.

Jane left the office of the association and directly went to the district office to meet the district community development officer at the entrepreneurship department. At this office she was told that if she can find experts to help her with the task of identifying related inefficiency problems of these craftsmen which need solutions, then the district office will provide necessary funding for the experts. She left the office thinking about how to get the needed experts. Jane decided to call a friend who is a professor in industrial engineering at one university in her previous city of residence to ask for possible approach to help her identify the problems. The professor finds it interesting and promises to send four senior $\mathrm{PhD}$ students with different related expertise related to small industries to do the research. But these students 
need some financial support related to transport and accommodation. Jane confirmed to the professor about the financial support that will be fully compensated by the district office. A week after, the PhD students were sent that under supervision and through mediation of Jane could consult the craftsmen and do some necessary research. After one month, a report was handed by Jane to the district office and the association of senior professionals. The report identified a number of problems, among others; they included lack of steady suppliers of raw materials, lack of capital, lack of needed workers, and poor marketing. The report also suggested some needed specialized training for craftsmen.

The association of senior professionals then used the report to form a few teams of professionals, e.g. for training and providing advice on financial and economical aspects to the village craftsmen, etc., who started their work. One main achievement requested by the district was that the craftsmen should be then capable to produce and sell beyond their village(s) and even in other regions where such traditional technology is lacking. Furthermore, the report motivated the district office and asked Jane to continue collaborating with the association of senior professionals to find possibilities and propose projects that will deliver solutions to existing problems in that village and others in the region. The projects were then be fully funded by the district office. Jane was happy not only because she has found a solution for people in her village but also that she will now have a formal job for a relatively longer period.

Challenges: There is a gap between providers of services (i.e. senior professionals and their associations) and recipients of services (SMEs, and young professionals). This gap needs to be filled with a third party (i.e. intermediaries) in order to smooth the needed interactions. A third party can be a government organization, an NGOs, an individual professor or researcher, or small consulting business, etc., who can support on one hand pinpointing the problem that can be solved by senior professionals and on the other hand mediating it to be solved. There is also a gap in the definition of who is a senior professional. At the moment the term "senior professional" is being defined on the bases of the retirement age. Is Jane who faced redundancy but has not reached retirement age a senior professional? Therefore, some challenges include:

(i) Proper establishment of roles and responsibilities of the three parties, namely: SMEs, the association of senior professionals, and the intermediary elements must be addressed.

(ii) Establishing a clear definition of the term "senior professional" that can be contextually tuned to meet the need of a particular geographical area.

\section{Scenario 3: A service market portal}

Manuel just finished his breakfast and while enjoying this lovely morning of early Spring, he is now logging in the ProSolve portal. ProSolve is an electronic market place for innovation and problem solving allowing a community of retired highly skilled professionals to address problems and innovation challenges posted by client companies. A number of mechanisms are implemented in this marketplace, including:

- Open innovation challenges: A company looking for new ideas and potential solutions places a "challenge" in the market and indicates the associated monetary value. Members of the pool of experts of ProSolve can offer ideas / solutions (bid) on a confidential basis. The author of the idea / solution picked by the client company will be the one to be paid.

- Target problem solver: A company wants to find an expert with the right profile to perform a specific problem solving task. ProSolve helps matching potential experts with the requested expertise and facilitates the negotiation and contractual arrangements as well as other due diligences.

- Assistance / coaching: A company needs consultancy / coaching on some best practice. Potential experts are identified by ProSolve (matching mechanisms) and when agreement is reached the task is contracted. ProSolve plays an important role in all issues related to confidentiality, intellectual property, contractual aspects, and quality monitoring. After browsing over the new opportunities, Manuel found an interesting challenge and started digesting a solution based on his accumulated experience but also considering the pleasure of competing to offer a wining idea.

Two weeks later, Manuel received the great news that his idea was selected. Wow! He had been participating in other challenges before without being selected ... nevertheless he continued just for the pleasure of exercising his knowledge and experience. But now, the 10000 euros reward for his solution are certainly much welcomed and right on time to plan his summer holidays! While enjoying the news of the day, another idea came to his mind: It would be much more interesting if ProSolve evolved from a marketplace to a real community offering social networking aspects and also mechanisms for teaming up with our experts to work together on a problem instead of being alone ...

Challenges: A number of e-market places along these ideas are in fact emerging lately. Examples are the www.innocentive.com and the www.yourencore.com. While the first one is general purpose, i.e. open to active professionals, the second one is specifically focused on retired professionals. Nevertheless these 
initiatives, although showing signs of success, still lack some important features:

(i) Social networking or virtual community mechanisms are quite limited.

(ii) Brokerage (opportunity finding) is limited; only the portal management organization acts as a broker. Mechanisms to extend the brokerage potential (and the inclusion of other specialized actors) could increase the number of offers.

(iii) In most cases activities are performed by single individuals, not teams. In some cases the concept is even one of competition. Mechanisms for formation of teams, combining different skills, to better jointly address a problem would improve the quality of the outcomes.

Through the analysis of these three scenarios and many more others (www.epal.eu.com) we have identified the main entities within the ePAL environment that need to be properly modeled. The models will support achieving a thorough understanding of the environment and its constituents. Based on the results of the analysis of a set of scenarios and the comprehensive study of the baseline materials for this environment, in Section 4 we present the modeling of the ePAL environment.

\section{Modeling and Characterization of CASPs}

With the study of scenarios, as exemplified in Section 3, we have achieved a better understanding of many distinguishing structural, componential, functional and behavioural aspects of the ePAL environment which enable us to address the identification of its constituent elements, and to model its features and components.

\subsection{Main Elements of the ePAL Environments}

From the lessons learned through the above scenarios, a 1st model of the ePAL environment is developed, to help fully understand this environment. This model addresses the following five elements, as shown in Fig. 1, namely: (A) senior professionals, (B) teams of senior professionals, (C) communities of active senior professionals, (D) intermediaries, and $(\mathrm{E})$ recipients.

A: Senior professionals: These are retired professionals who are willing to provide services in terms of experiences and expertise either directly to the customer as individuals or through TSP configured within CASPs. SPs are encouraged to join CASP in order to increase their chances of getting involved in potential TSPs established within the CASP. The categories for senior professionals include: technicians, knowledge workers, managers, and specialists.

B: Teams of senior professionals: This is another fundament element of ePAL environment which refers to a group of senior professionals temporarily joining their efforts to provide services to a particular recipient. It is a collaborative network of individuals configured and established within the CASP in response to opportunities in the society and market that are in need of their wisdom and/or knowledge assets that they can offer, which as a consequence supports the retired professionals remaining professionally active. Based on how the services are provided and the possible agreements between the recipient and the TSP, we have characterized TSPs into four types, namely TSP operating on: (1) Competitive business activities (market profit), (2) Service business activities (small profit or cost compensation), (3) Voluntary activities (no form of payment) and (4) Voluntary and/or paid involvements (combining the three above possibilities). 


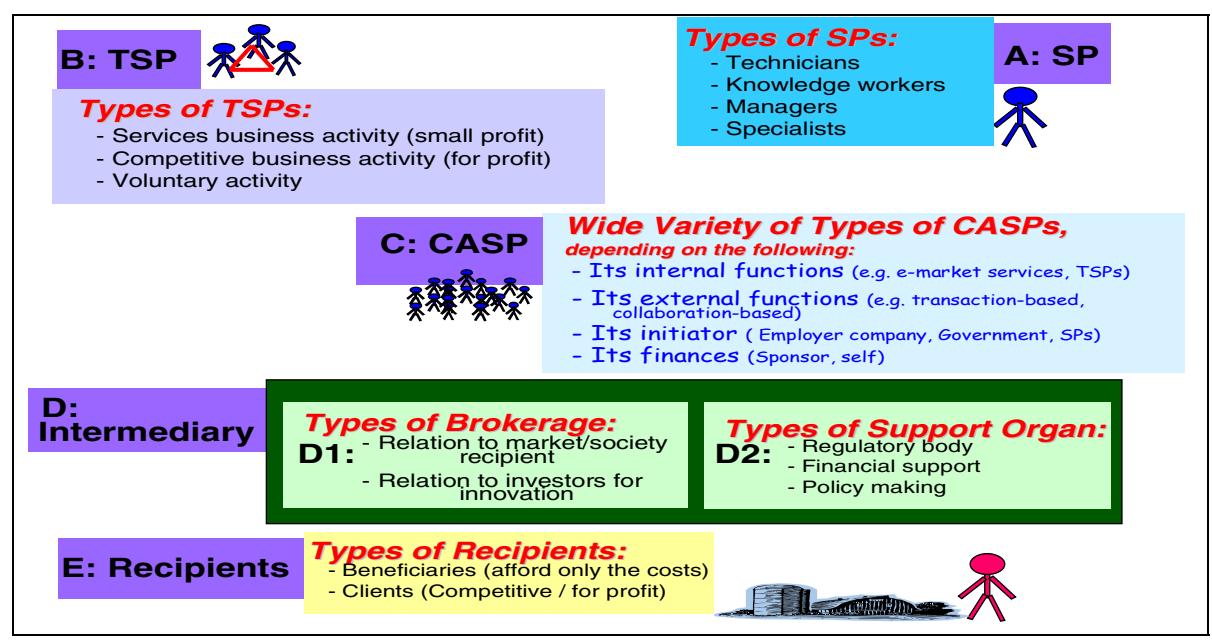

Fig. 1. Main elements of the ePAL environment

C: Communities of senior professionals (CASPs): This is a fundamental element of ePAL environments which constitutes an association of the retiring and retired people who are willing to provide some services to the market/society in response to demands of recipients. Thus a CASP constitutes an association of SPs that are largely autonomous, geographically distributed, and potentially heterogeneous in terms of their: capabilities, offered capacities, culture, system of values, etc., but sharing their main compatible and/or common goals of increasing their active professional life in the society and/or market, through co-working with others in TSPs supported by computer networks. A number of different types of CASPs can be established but they can be distinguished on the basis of the following four characteristics:

1- Related to its internal functions: (1.A) E-market (provision of ready made services) and (1.B) Virtual Organization (team-based new developments).

2- Related to its external functions: (2.A) Transaction-based (sale of products/services) and (2.B) Collaboration-based (customer involved design/development).

3- Related to how it is initiated: (3.A) Employer-initiated (by large / very large organizations), (3.B) Government-initiated (regional / national initiatives), and (3.C) Seniors-initiated (brokered by senior professionals).

4- Related to how it is financed (main source): (4.A) Sponsors (government, large companies, etc.), and (4.B) Self financed - based on commission from profit, subscription fees,...

D: Intermediaries: These are organizations which act as mediators or agents between CASP (or individual SPs) and recipients. Intermediaries are mainly responsible for two fundamental tasks, namely: (D1) Broker organization: Brokering of opportunities that can be responded by CASP through configuration of TSPs. The brokered opportunities can also be responded by individual SPs, and (D2) Support organization: Establishing conditions that will support CASPs, TSPs and individual SPs to 
smoothly interact with recipients, such as regulatory bodies, national/international policy making bodies, etc.

E: Recipient: These can range from individual people, groups of people, SMEs, or large organizations. Recipients include the two categories of clients and beneficiaries. Clients constitute competitive organizations that are able to pay for the services provided by SPs. Beneficiaries on the other hand are those recipients that are not able to afford the costs of the services they require, so these recipients seek SPs that can provide voluntary services, for which only the actual costs are paid.

\subsection{Towards Establishing a Model of ePAL Environment}

Based on the identified elements of the ePAL environments as presented in Section 4.1, we have developed a 1st model for the ePAL environment as shown in Fig. 2. This model can be used as a "reference" for the specification of our ePAL environment vision. The model addresses a variety of kinds of involvements from active SPs, shown as SPs in Fig. 2, in the market and society, thus capturing the structure of both the present involvements as well as future potential involvements.

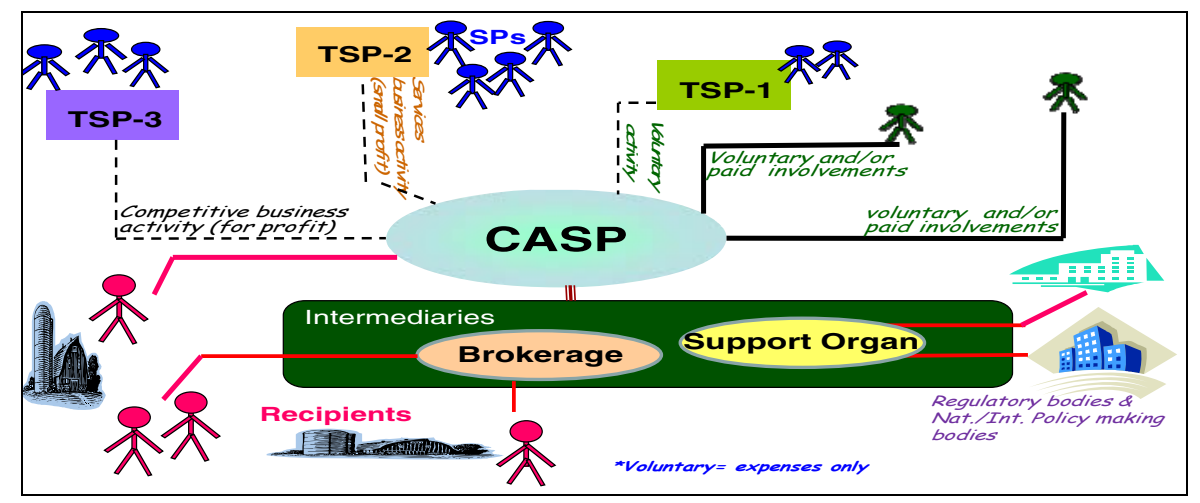

Fig. 2. A 1st model of the ePAL environment

In other words, currently the activities of senior professionals, being voluntary or paid involvement, are concentrated on either: (i) One to one contact with a recipient, as established through simple intermediaries e.g. a regional governmental offices, or (ii) Some regional elderly professional clubs (the early emergence of CASPs) that again connects a senior professional directly with one recipient.

But there are already a few cases in Europe when a team of senior professionals from within an association of senior professionals, and together deliver a service to the market/society. Therefore for the future of the ePAL environment the following structures are foreseen: (1) Team-work type of activities, as specified above by the three kinds of TSPs, (2) Stronger and more pro-active establishment for the CASPs and its administration and involvement in the market/society, and (3) Presence of Brokers and brokerage of senior professional activities as a strong intermediary between the senior professionals and the market/society. 


\subsection{Modeling Needs for ePAL Environments}

A rough summarization of all scenarios studied has revealed a number of areas in need of attention and consideration for the development of the $1^{\text {st }}$ ePAL vision. These areas point to the main lines of related research and development that must be performed in the coming years to support making the desired vision of ePAL a reality. The four main areas in need of great attention within the ePAL vision consist of (see Fig. 3): Reference model, Operational model, Public relation model, and Socialization and trust building model.

Specification of a first model for ePAL environment: A Reference model is a computer science term that describes an abstract framework for understanding significant relationships among the entities of an environment, and for the development of consistent standards or specifications supporting that environment [7, 10]. A reference model is based on a small number of unifying concepts and may be used as a basis for education and explaining standards to a non-specialist. Therefore, reference models are not directly tied to any standards, technologies or other concrete implementation details, but they aim to provide a common semantics that can be used unambiguously across and between different implementations. Research on developing a reference model for ePAL environment shall result:

- The ePAL environment: A specification classifying the constituents of the ePAL environment into endogenous and exogenous elements [1]. The endogenous elements include those elements related to the structural, componential, functional and behaviour aspects of the CASPs. The exogenous elements include elements related to the market, support, societal and constituency aspects of CASPs.

- Specification of inter-relationships between entities of the ePAL environment: Focuses on defining all entities as well as their roles and responsibilities which guide the nature of their interactions within the CASPs. The inter-relationships / interactions between entities, among others, may include the following: (1) How they operate within the ePAL environment (Operational model), (2) How they relate to the outside environment (public relation), and (3) How they share and exchange information and knowledge (socializing and trust building).

Operational model: An operational model for a business is a schematic element which shows the operating units for the business and the relationships between these operating units. It describes how an organization operates across both business and technology domains. CASPs and TSPs focus on providing services in the market / society e.g. in terms of packages of advice and expertise from SPs. Therefore, an operational model is needed to be researched and developed, for instance for CASPs to on one hand guide the establishment of ICT support and on the other hand to guide the governance and working principles of these associations as shown in Fig. 3.

Public relation model: Public relation is the practice of managing the flow of information between an organization and its public. It facilitates gaining exposure for organizations to their audiences, recipients, partners etc. by addressing public interests that relates to organizational operations as well as the external interactions. A public relation model shall address and provide guidelines on how these aspects can be realized within and between organizations. Particularly, for ePAL environments, such as CASPs, the public relation model shall address: (i) Interaction with senior professionals (socializing, 


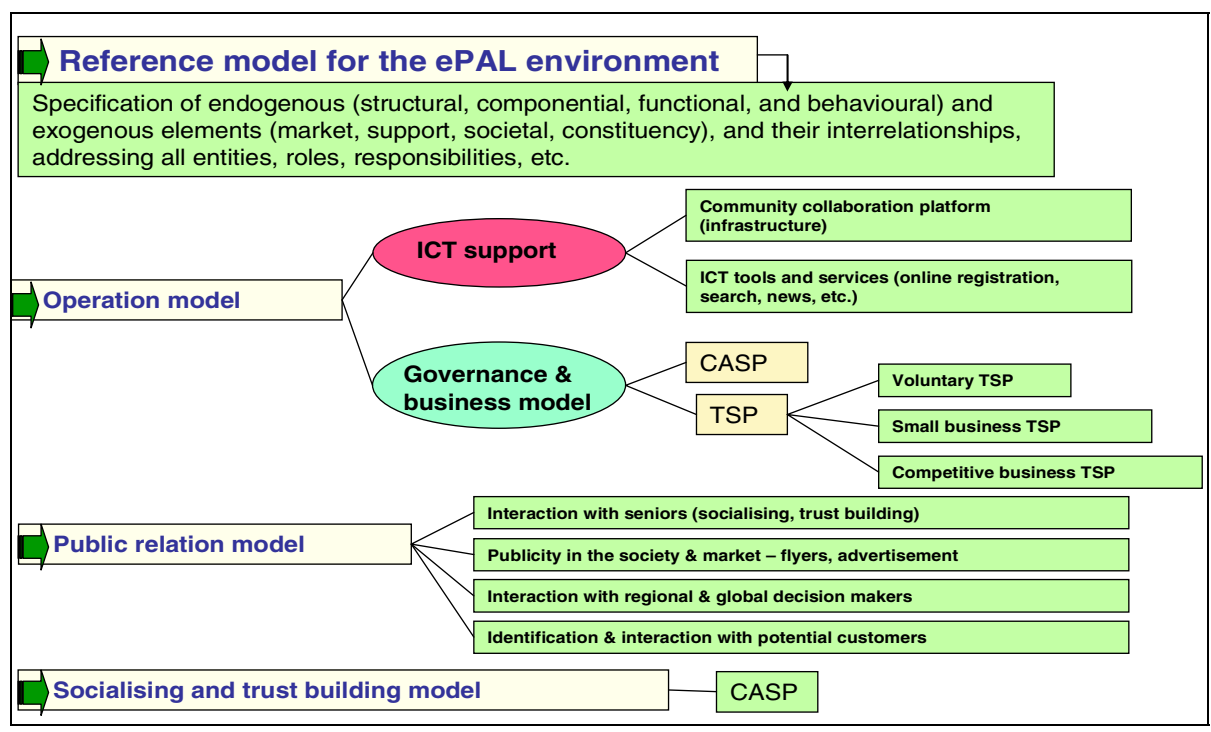

Fig. 3. Some lessons learned related to modelling

trust building), (ii) Publicity in the society and market (flyers, advertisements), (iii) Interaction with regional and global decision makers, and (iv) Identification and interaction with potential customer.

Socialization and trust building model: A fundamental aim of CASPs is to support SPs remain active in their life. One key aspect necessary for SPs to remain active is to continue socializing between each other, as well as with the entire society. An enabler to the needed socializations among SPs is the existence of trust among them. This model shall guide the creation of trust among SPs and from the society towards the SPs and their professional activities.

\subsection{The Visioning Related Worlds of ePAL Environment}

In order to properly position the ePAL environment within the European society, we need to carefully analyze different kinds of involved organizations and classify them on the basis of their relation to the operation and interaction with CASPs, TSPs, and SPs. Based on the empirical study of existing associations of SPs, extensive requirement analysis for the ePAL environment, identification of the environment trends and drivers, as well as lessons learned from the variety of developed scenarios, we have classified the elements within the general environment of ePAL into three groups, each labelled as one "world" through which the ePAL vision will take us, namely (1) the world of knowledge and talent, (2) the world of mediation and support, and (3) the world of recipients and innovation (Fig. 4):

1. World of knowledge and talent: Constitutes individuals such as professional freelancers, group of individuals such as professional virtual communities, organizations such as universities, etc. which act as sources of knowledge that are needed in the market for providing required services. It is in this world from which the SPs originate. 


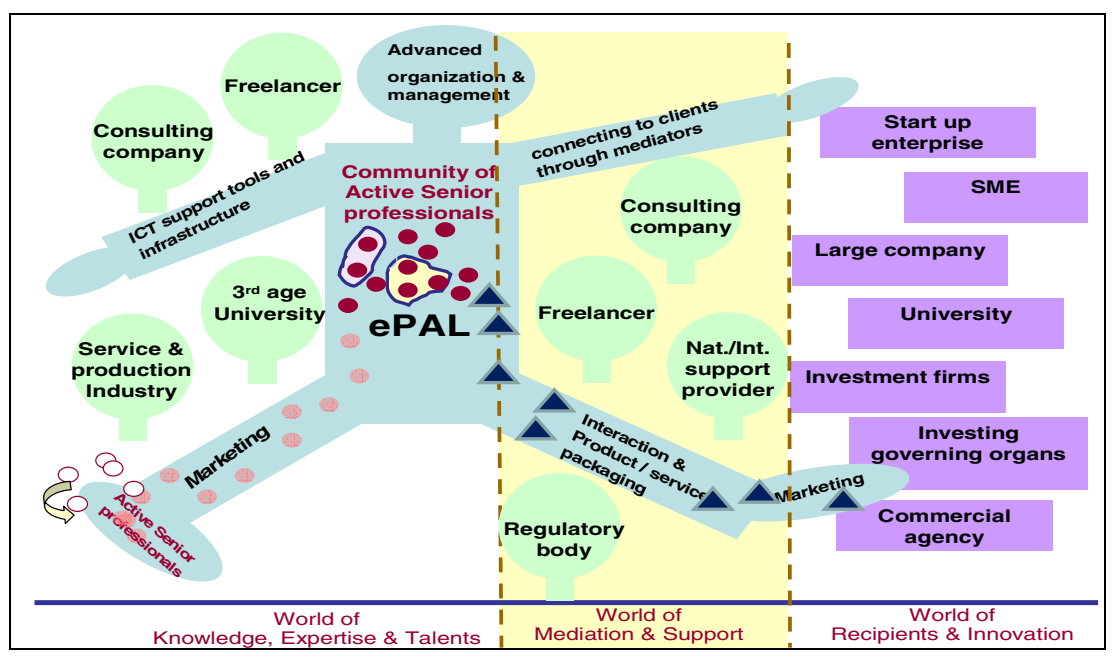

Fig. 4. Lessons learned - vision of ePAL in future

2. World of mediation and support: Constitutes the intermediary organs of a wide spectrum from the governmental and decision making bodies to the consulting companies that find/create the market for SPs with the Market and recipients. Therefore, elements in this world support SPs and other collaborating parties, with variety of assistance, e.g. potentially connecting them with recipients, paving the road through establishing needed laws and policies and in delivering required services into the market among many others. Intermediary organs can be consulting companies, freelancers, national and international organizations, regulatory bodies, etc.

3. World of recipients and innovation: Constitutes the people and organizations that need the services and expertise which can be provided by the senior professionals either as an individual or through TSPs and CASPs. Recipients may include start-up enterprises, SMEs, large companies, as well as investing firms or government organs that may finance their activities and even support their potential initiatives for innovation. Besides providing packaged services to this world, SPs can establish different forms of co-working and co-development with entities of this world.

Considering these three worlds, we can conceptually design the target for the vision of ePAL environment, visualized as a person walking through these three worlds. First, the vision shall focus on the development of strong communities of retired professionals, supported by advanced organization and management systems, referring to the body and the head of the ePAL vision. Then the strategic plans of each community established to promote active life of SPs, would be to on one hand attract and motivate the active SPs into joining this community, namely the right foot of the ePAL vision, and provide ICT support tools and infrastructure to enable the SPs with contribution of their knowledge and talent, namely the right hand of the ePAL vision. On the other hand absorbing the support and opportunities provided through the mediation and support world, the community can connect to the potential recipients through the mediators, namely the left hand of the ePAL vision, and interact with them, providing products and services, namely the left foot of the ePAL vision. 


\section{Conclusion}

Development of comprehensive models for ePAL environment is an important base for the elaboration of these environments, a base element in the consolidation of existing knowledge in this area, and a base for its consistent progress. As a contribution in this direction, this paper has addressed the characterization of the ePAL environment by: (1) proposing the fundamental elements that must be considered for developing a comprehensive model of the environment, (2) developing a $1^{\text {st }}$ model of the environment and (3) identifying fundamental modelling needs of the environment. As a next step to this research, the ARCON model shall be developed for the ePAL environment.

Acknowledgements. This work was funded in part by the European Commission through the ePAL project. The authors thank the contributions from other partners in the project.

\section{References}

1. Afsarmanesh, H., Camarinha-Matos, L.M.: The ARCON modeling framework. In Collaborative networks reference modeling, pp. 67-82. Springer, New York (2008)

2. Afsarmanesh, H., Camarinha-Matos, L.M.: Related work on reference modeling for collaborative networks. In: Collaborative networks: reference modeling, pp. 13-28. Springer, Heidelberg (2008)

3. Camarinha-Matos, L.M., Afsarmanesh, H.: The need for a strategic R\&D roadmap for active ageing. In: The proceedings of PRO-VE 2009 conference (September 2009) (to appear)

4. Barnett, M.W., Miller, C.J.: Analysis of the virtual enterprise using distributed supply chain modeling and simulation: An application of e-SCOR. In: Joines, J.A., Barton, R.R., Kang, K., Fishwick, P.A. (eds.) Proceedings of the 2000 Winter Simulation Conference (2000)

5. Camarinha-Matos, L.M., Afsarmanesh, H.: The need for a strategic R\&D roadmap for active ageing. In: The proceedings of PRO-VE 2009 conf. (September 2009) (to appear)

6. Camarinha-Matos, L.M., Afsarmanesh, H.: Motivation for a theoretical foundation for collaborative networks. In: Collaborative networks: reference modeling. Springer, Heidelberg (2008)

7. Camarinha-Matos, L.M., Afsarmanesh, H.: Towards a reference model for collaborative networked organizations. In: Information Technology for Balanced Manufacturing Systems, vol. 220, pp. 193-202 (2006) ISBN 978-0-387-36594-7_21

8. EGA. Enterprise Grid Alliance Reference Model (April 13, 2005), http: //www.gridalliance.org/en/workgroups/ReferenceModel.asp

9. FEA. FEA Consolidated Reference Model (2003) (May 2005), http: / / www . whitehouse.gov/omb/egov/documents / CRM. PDF

10. OASISI: Integrated Collaboration Object Model for Interoperable Collaboration Services (2008), http: / / www. oasis-open.org/committees / icom/charter.php

11. Zwegers, A., Tolle, M., Vesterager, J.: VERAM - Virtual enterprise reference architecture and methodology. In: Proceedings of GLOBEMEN - Global Engineering and Manufacturing in Enterprise Networks, VTT Symposium, vol. 224 (2003) 